\title{
PP29
}

\section{TESTING THE USE OF SPECTRALLY TUNABLE LIGHTING SYSTEMS TO IMPROVE COMFORT, ALERTNESS AND SLEEP QUALITY IN INDOOR WORKING ENVIRONMENTS}

\author{
Aleix Llenas et al. \\ DOI 10.25039/x46.2019.PP29 \\ from \\ CIE x046:2019 \\ Proceedings \\ of the \\ 29th CIE SESSION \\ Washington D.C., USA, June 14 - 22, 2019 \\ (DOI $10.25039 / \times 46.2019)$
}

The paper has been presented at the 29th CIE Session, Washington D.C., USA, June 14-22, 2019. It has not been peer-reviewed by CIE.

(C) CIE 2019

All rights reserved. Unless otherwise specified, no part of this publication may be reproduced or utilized in any form or by any means, electronic or mechanical, including photocopying and microfilm, without permission in writing from CIE Central Bureau at the address below. Any mention of organizations or products does not imply endorsement by the CIE.

This paper is made available open access for individual use. However, in all other cases all rights are reserved unless explicit permission is sought from and given by the CIE.

CIE Central Bureau

Babenbergerstrasse 9

A-1010 Vienna

Austria

Tel.: +4317143187

e-mail: ciecb@cie.co.at

www.cie.co.at 


\title{
TESTING THE USE OF SPECTRALLY TUNABLE DYNAMIC LIGHTING SYSTEMS TO IMPROVE COMFORT, ALERTNESS AND SLEEP QUALITY IN INDOOR WORKING ENVIRONMENTS
}

\author{
Llenas, A. ${ }^{1,2 *}$, Hurlbert, A. ${ }^{3}$, Lam, F. ${ }^{4}$, Manudhane, R. ${ }^{4}$, Gaurav, G. ${ }^{3}$, Giddings, J. ${ }^{4}$, Carreras, J. ${ }^{2}$ \\ ${ }^{1}$ Institut de Recerca en Energia de Catalunya (IREC), Barcelona, SPAIN, ${ }^{2}$ Ledmotive Technologies \\ SL, Barcelona, SPAIN, ${ }^{3}$ Newcastle University, Newcastle upon Tyne, UNITED KINGDOM, ${ }^{4}$ Arup, \\ London, UNITED KINGDOM. \\ *allenas@ledmotive.com
}

DOI 10.25039/x46.2019.PP29

\begin{abstract}
Lighting installations in offices and buildings are typically static and specified in terms of their effects via the classical visual pathway (e.g. chromaticity or brightness). It is now recognised that spectral variations in light elicit non-visual effects, including on emotion and cognition, via a distinct neural pathway, and it is important for health and wellbeing to take these into account.

This article describes the aims and methodology of an experiment designed to test whether dynamic sculpting of the light spectra in indoor environments, either to mimic natural daylight changes or achieve particular levels of non-visual vs. visual stimulation, may elicit different biological and behavioural effects. Subjective and objective measurements are used to assess the behavioural responses resulting from exposure to custom-made, dynamically changing light spectra sequences that are produced by a spectrally tunable lighting system, and to compare these with responses to a traditional fluorescent lighting system. The viability of the study is qualitatively evaluated here; quantitative results will be reported elsewhere.
\end{abstract}

Keywords: spectrum, colour, LED, metameric, CCT, melanopic lux, melanopsin, lighting, smart lighting, tunable, multi-channel

\section{Introduction}

The modern human visual system evolved under exposure to natural daylight only, for millennia. Natural daylight is a mixture of light from the sun and sky, containing energy at all wavelengths in the visible spectrum. Since the invention of the candle, perhaps 2500 years ago, humans have become more reliant on artificial lighting technologies, and increasingly so in the past century after the development of electric light, with more activities being performed indoors, significantly shortening the daily exposure to natural light.

In the design of illumination for indoor spaces, it has traditionally been only the well-established visual effects of light that are considered, such as illuminance, glare, chromaticity or correlated colour temperature (CCT), and colour rendering indices (e.g. CRI or TM-30). Yet the recent discovery of the intrinsically photosensitive retinal ganglion cells as the origin of the non-visual pathway that entrains biological rhythms to the light/dark circadian cycle (LUCAS et al., 2014) (BERSON et al., 2002) has started a new drive to characterise lighting in terms also of its nonvisual effects on human behaviour. This non-visual pathway is responsible not only for regulating the circadian rhythms of body temperature, melatonin secretion, and the overall sleep/wake cycle, but also for modulating cognitive function, attention, and mood (CAJOCHEN, 2007) (CHELLAPPA et al., 2011) (BADIA et al., 1991). Although it has long been known that the entraining light signal emanated from the retina (SCHEER, 1999) (LEWY et al., 1980) it was not until the discovery of the ipRGCs (BERSON et al., 2002) (VANDEWALLE et al., 1996) and the characterisation of the melanopsin photopigment they contain that the importance of spectral variations in light for eliciting non-visual effects was fully recognised. The spectral sensitivity of melanopsin peaks at $480 \mathrm{~nm}$, midway between the short- and middle-wavelength cones, but is broad-band and overlaps with that of all four classical photoreceptors. Modulation of the short-wavelength ("blue") content of light has been shown to affect various physiological measures such as melatonin suppression, alertness, thermoregulation, heart rate, cognitive 
performance, and electroencephalographic dynamics (BONMATI-CARRION et al., 2014) (REVELL et al., 2007).

The effectiveness of a given light spectrum in activating the non-visual pathway may be quantified by its melanopic lux, the spectral irradiance weighted by the melanopsin spectral sensitivity function and integrated over wavelength (Lucas et al. 2014), or by functions of the same (e.g. CS, REA et al. 2010). Melanopic lux is therefore an appropriate characteristic of illumination to consider in addition to visual factors such as photopic lux or CCT.

Currently, the most common artificial light sources are fluorescent lights and white LEDs which are all static sources with spectra very different from natural daylight. The recent invention of narrow-band LEDs enables the development of spectrally tuneable light sources that are able to generate illuminations with arbitrary spectral shapes, and therefore to mimic daylight spectral patterns or create tailored dynamic spectral sequences according to the end-user needs (SCHUBERT, 2005).

Previous studies have compared the performance of individual subjects under different artificial lighting conditions (e.g. VIOLA et al., 2008). Such studies, though, have used only two types of white light, both fixed in time: cool blue-enriched fluorescent light and warm fluorescent light, and have not exploited the novel spectral flexibility obtainable from multi-channel LED light sources.

In this study, and for the first time in a real office setting, the behavioural effects of a dynamic spectrally tunable lighting system are investigated and compared to a traditional fixed fluorescent lighting system. The study includes assessments of alertness, mood, sleep quality, performance, mental effort, and other responses to different dynamic illumination conditions in a 9-week intervention using subjective and objective measurements.

\section{Experiment design}

This experiment aims to investigate the effects of novel spectrally tunable light-engines that produce custom-made dynamic illumination sequences during daytime workhours in an office setting. The aim is to assess whether sculpting different spectral power distributions (SPDs) of light may bring measurable benefits in terms of well-being and productivity in an indoor workplace installation, and, more generally, to understand better the behavioural effects of different lighting conditions in indoor environments and raise awareness of the importance of a circadian lighting approach.

This investigation took place from February $18^{\text {th }}$ to April $19^{\text {th }} 2019$ at a multinational professional services firm headquartered in London, United Kingdom. An area of approximately 160 square meters was selected, comprising the working desks of 24 people. A set of 36 downlighter luminaires containing LEDMOTIVE (model VEGA07) tunable light engines were installed into ceiling panels alongside the pre-existing fixed fluorescent light tubes. External light sources were blocked by completely covering the windows along one wall, and inserting a scrim between this space and the adjacent working area (see Figure 1). 


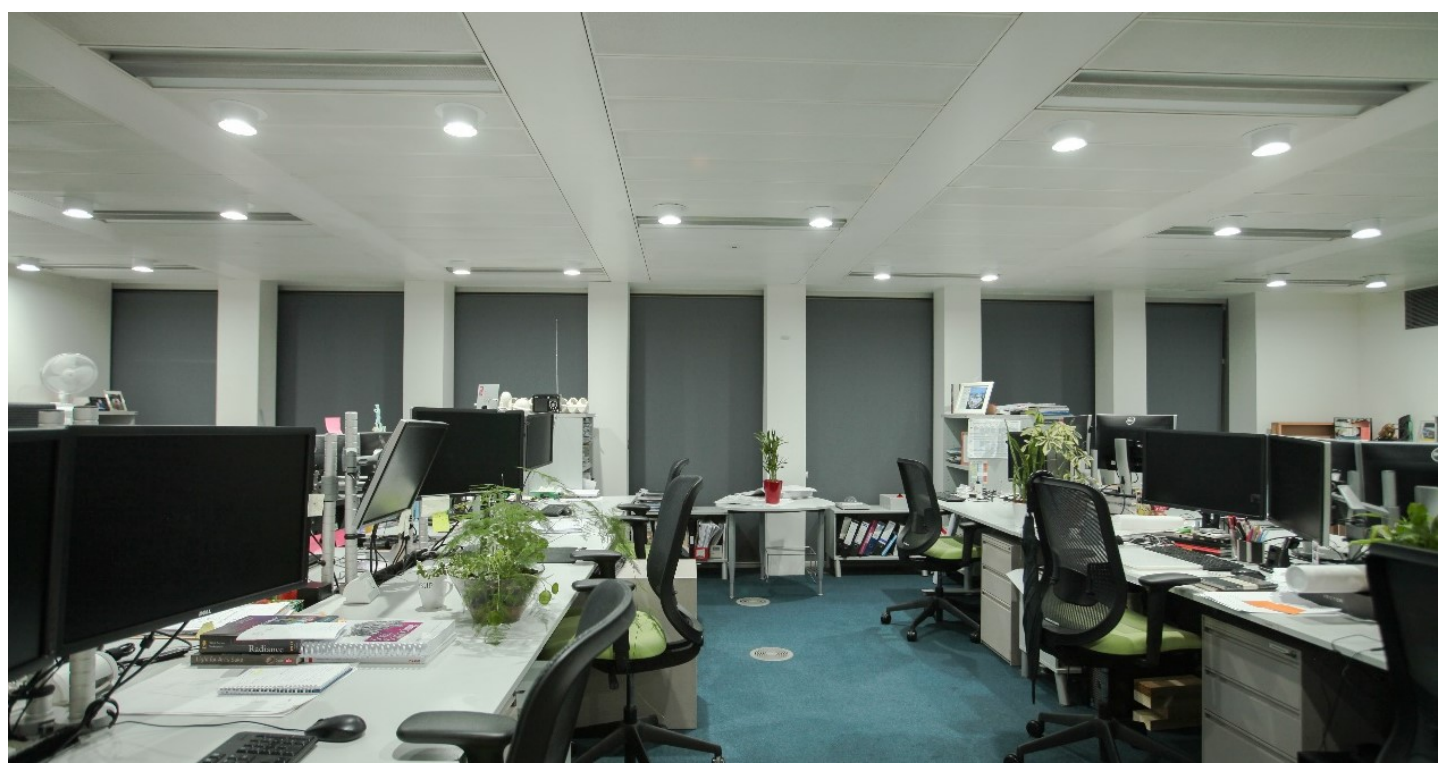

Figure 1 - Photograph of the office with Ledmotive's spectrally tunable lighting system installed.

The habitual start and end time of the workday are 08:00 and 18:00, respectively. Sunrise varied from 07:09 at the beginning of the study period to 05:57 at its end; dusk varied from 17:20 to 20:03. Thus, for most of the study, dawn and dusk happened outside the workhours, and exposure duration to light during this period, including the commute time to and from work, will have varied from the beginning to the end of the study.

The study duration was 9 weeks. The lighting conditions were: first, 2 weeks under the preexisting traditional fluorescent lights only (baseline); second, 2 weeks under the spectrally tunable light sequence A; third, 2 weeks under the spectrally tunable light sequence B; fourth, 1 week of the spectrally tunable lights mimicking the baseline traditional fluorescent lights output; and, lastly, 2 weeks under the spectrally tunable lights mimicking the current daylight patterns. Light sequence A had temporally changing melanopic lux, photopic lux and CCT during the day, with melanopic lux falling from a high of 450 in the morning to a low of 160 in the evening, photopic lux falling from 500 in the morning to 300 in the evening, and the CCT changing from cool (6000) to warm (2500) over the same interval. Light sequence B matched light sequence $A$ in terms of its changing melanopic lux, but kept constant photopic lux and CCT at levels matching the baseline fixed fluorescent lights. Table 1 summarizes the different light conditions and the parameters (CCT, photopic lux and melanopic lux) that remain static or changing.

Table 1 - Summary of the trial's light conditions.

\begin{tabular}{|c|c|c|c|c|c|}
\hline Light condition & Duration & Dates & Photopic lux & Melanopic lux & CCT \\
\hline $\begin{array}{c}\text { Baseline (Fluorescent } \\
\text { lights) }\end{array}$ & 2 weeks & $\begin{array}{c}\text { February } 18^{\text {th }} \text { to } \\
\text { March } 3^{\text {rd }}\end{array}$ & Static $(350 \mathrm{Ix})$ & Static $(160 \mathrm{Ix})$ & Static $(3534 \mathrm{~K})$ \\
\hline Sequence A & 2 weeks & $\begin{array}{c}\text { May } 4^{\text {th }} \text { to May } \\
17^{\text {th }}\end{array}$ & $\begin{array}{c}\text { Changing }(500 \mathrm{Ix} \\
-300 \mathrm{Ix})\end{array}$ & $\begin{array}{c}\text { Changing }(450 \mathrm{Ix} \\
-160 \mathrm{Ix})\end{array}$ & $\begin{array}{c}\text { Changing }(6000 \\
\mathrm{K}-2500 \mathrm{~K})\end{array}$ \\
\hline Sequence B & 2 weeks & $\begin{array}{c}\text { March } 18^{\text {th }} \text { to } \\
\text { March } 31^{\text {th }}\end{array}$ & Static $(350 \mathrm{Ix})$ & $\begin{array}{c}\text { Changing }(450 \mathrm{Ix} \\
-170 \mathrm{Ix})\end{array}$ & Static (3534 K) \\
\hline $\begin{array}{c}\text { Baseline (mimicking } \\
\text { fluorescent lights) }\end{array}$ & 1 week & $\begin{array}{c}\text { April } 1^{\text {st }} \text { to April } \\
7^{\text {th }}\end{array}$ & Static $(350 \mathrm{Ix})$ & Static $(160 \mathrm{Ix})$ & Static $(3534 \mathrm{~K})$ \\
\hline $\begin{array}{c}\text { Real-time daylight } \\
\text { matching }\end{array}$ & 2 weeks & $\begin{array}{c}\text { April } 8^{\text {th }} \text { to April } \\
19^{\text {th }}\end{array}$ & Changing & Changing & Changing \\
\hline
\end{tabular}


15 employees (age range 25 - 57; 6 males), having diverse roles within the company, volunteered to take part in the study. All participants completed health screening questionnaires, including screenings for sleep disorders, depression, anxiety, physical illness, and extreme chronotypes; none were excluded on the basis of these assessments. All gave their written informed consent prior to any study procedures. The participants were not informed of the specific lighting conditions to be used or the expected outcomes of the study.

\section{Subjective and objective measurements}

Throughout the study period, each participant took part in daily subjective and objective behavioural assessments as follows.

\subsection{Subjective measurements}

Participants were asked to complete web-based questionnaires at four timepoints (1-4) each weekday (Monday-Friday), and at two timepoints (1 and 4) on each day of the weekend (Saturday-Sunday) and holidays. Specifically:

- Waking (timepoint 1): Sleep diary, morning entry: after waking up, participants completed questions assessing the quality of the previous night's sleep.

- Morning (timepoint 2): Between 10:30 and 11:00h, participants completed a questionnaire combining the Karolinska Sleepiness Scale (KSS) (AKERSTEDT et al., 1004) (GILLBERG et al., 1994), the Rating Scale Mental Effort (RSME) (VERWEY et al., 1996) and Positive and Negative Affect Scale (PANAS) (CRAWFORD et al., 2004).

- Afternoon (timepoint 3): In mid-afternoon (16:00h), participants were asked to repeat the combined questionnaire of KSS, RSME and PANAS.

- Evening (timepoint 4): Before going to sleep, participants were asked to complete questions about sleepiness, mood, drinks and exercise during the day, and to assess their level of headache and eye strain.

Every Friday, participants were also asked to complete questions on their subjective experience of the lighting condition experienced that week.

\subsection{Objective measurements}

Subjective assessments were complemented with objective measurements. More specifically:

- Actigraphs recordings: All participants were asked to wear a wearable smart watch $24 / 7$ that keeps track of temperature, light exposure and activity levels.

- Short perceptual experiments: Participants completed a short (5 minutes) visual attention task at two timepoints ( 2 and 3 ) each weekday. The task was a continuous performance task which assessed sustained attention, implemented via a web-based JavaScript application, presented in black-and-white.

\section{Light conditions}

\subsection{Baseline}

The light conditions set for the first two weeks were regular fluorescent lights, some of the most used light sources in the world. Its spiky spectrum (see Figure 2, left) is very well-known and totally different from natural daylight. The office's fluorescent lights had a CCT of 3550K and typical values of photopic lux at the desktop were about $350 \mathrm{~lx}$. The melanopic lux for this light was about $160 \mathrm{~lx}$ at the desktop. During the $7^{\text {th }}$ week, when mimicking fluorescent lights with the spectrally tunable light source (see Figure 2, right), the light generated had the same parameters: CCT of $3550 \mathrm{~K}$, photopic lux of $350 \mathrm{Ix}$ and melanopic lux of $160 \mathrm{~lx}$ at the desk level.

Figure 3 shows that with these light conditions, the three indicators remain static during the whole working day. 

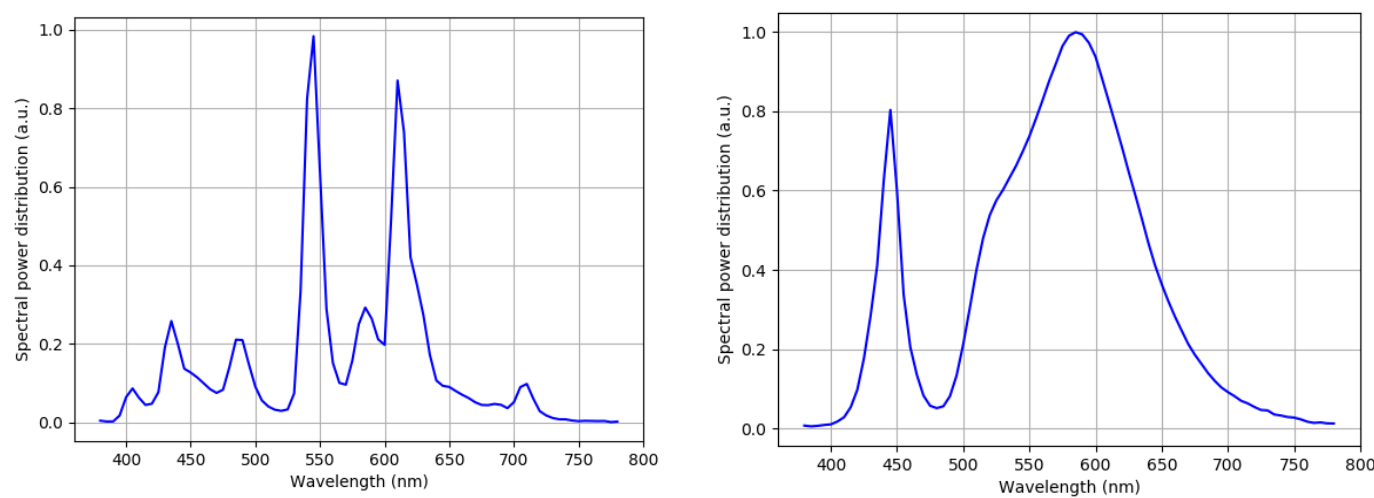

Figure 2 - Baselines: Real fluorescent lights SPD (left) and spectrally tunable light engine SPD (right). Both measured spectra have the same CCT of $3550 \mathrm{~K}$, same photopic lux of $350 \mathrm{Ix}$ and same melanopic lux of $160 \mathrm{Ix}$ at desk level.

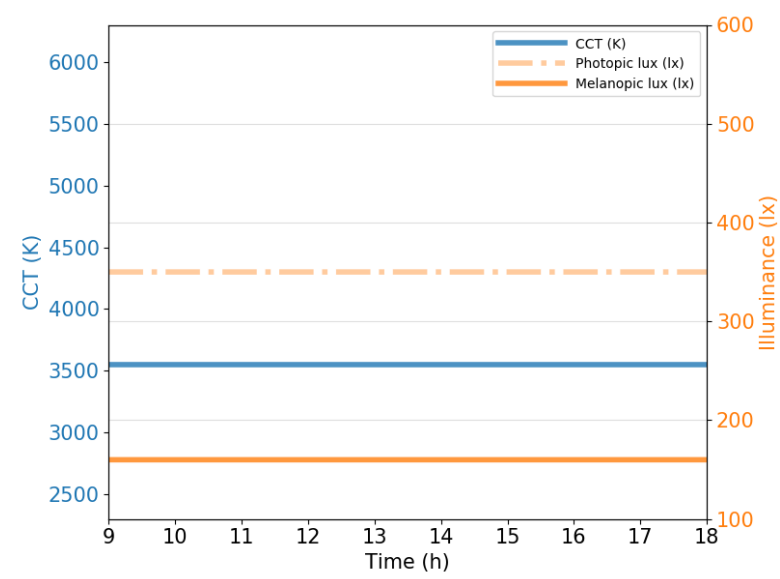

Figure 3 - In an office setting with only fluorescent lights, light indicators such as CCT, photopic lux or melanopic lux coming from the light fixtures remain static during the whole working day.

\subsection{Light sequences}

The LEDMOTIVE (model VEGA07) tunable light engine used for this experiment is composed of 48 commercial monochromatic LEDs arranged in 7 channels, each with a distinct peak wavelength, spread over the visible spectrum (see Figure 4).

a)

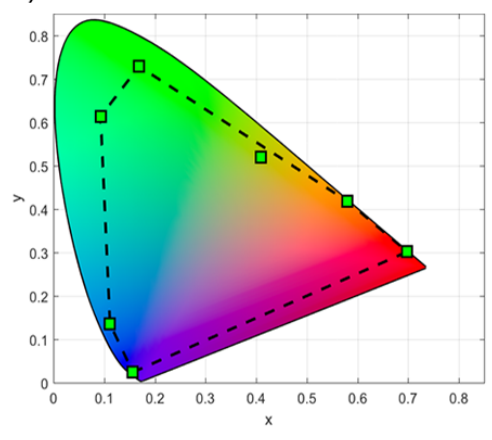

b)

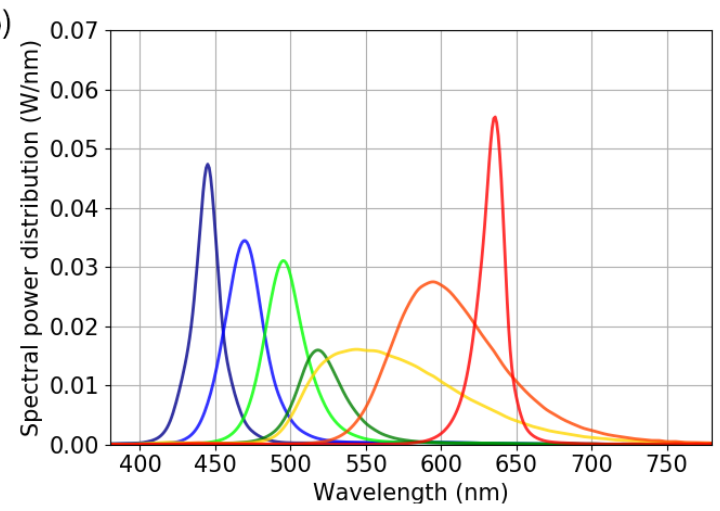

Figure 4 - CIE 1931 xy coordinates of the 7 channels that define the colour gamut (a) and the preset SPDs of the 7 LED channels (b). 
High melanopic lux in the morning is thought to lead to better attention and higher arousal, while low melanopic lux in the evening is suitable for relaxing and for better sleep at night (TE KULVE et al., 2017). This experiment adds to the existing knowledge by using spectrally tunable light systems with light sequences tailored to human needs. In this experiment, light sequence A was designed to change in CCT from cool in the morning to warm in the afternoon, and with photopic and melanopic lux values changing from high values in the morning to low values in the afternoon (see Figure 5). Sequence B was designed with the same visual parameters as baseline (same CCT and same photopic lux) but with changing melanopic lux values during the day (see Figure 6). By comparing sequence B with baseline, the experiment compared the effects of changing melanopic lux alone, with the other parameters remaining the same. With sequence $A$, we are able to test not only the melanopic lux effect, but also the effect of a concomitant changes in CCT, as the visual comfort and overall experience that the light fixtures evoke is also important for well-being.
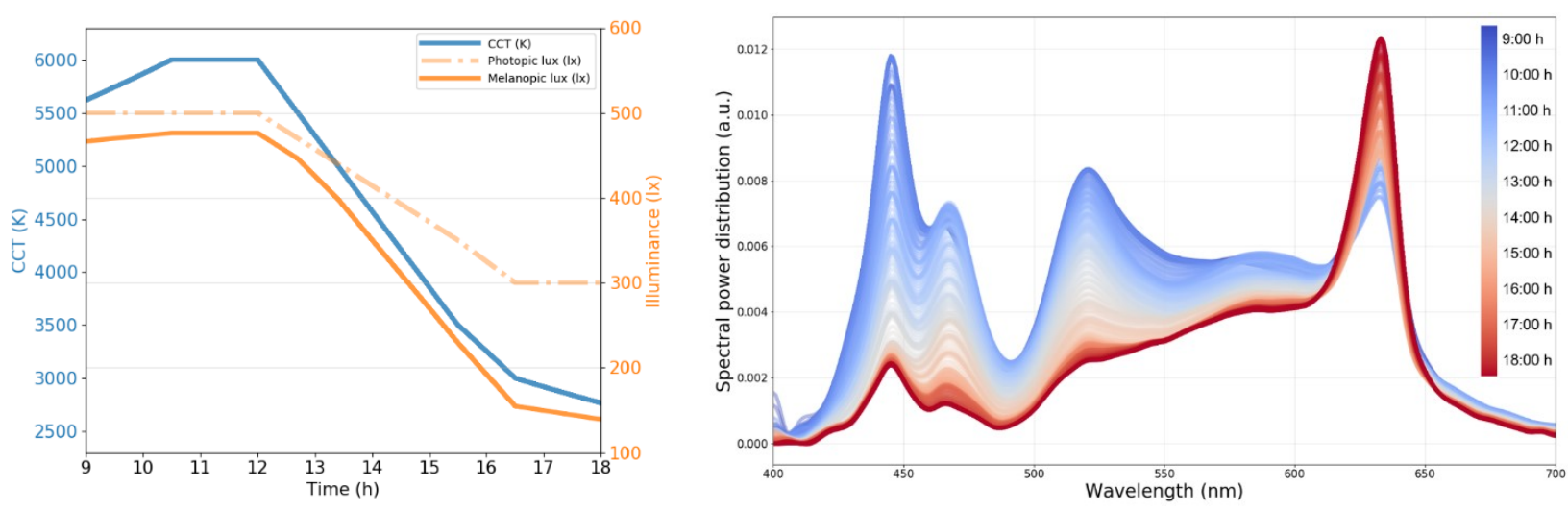

Figure 5 - (left) Sequence A was designed to have a changing CCT, changing photopic lux and changing melanopic lux during the day. (right) In-situ measured spectra from Sequence $A$ SPD, varying from 9 am (blue) to $6 \mathrm{pm}$ (red).
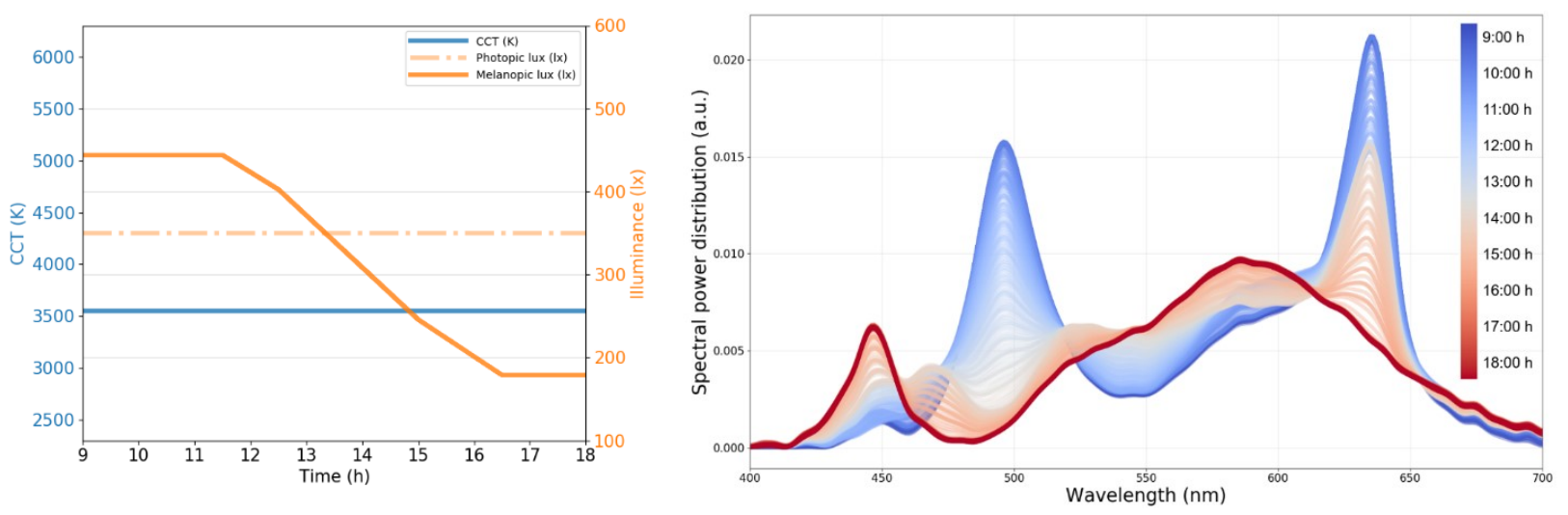

Figure 6 - (left) Sequence B was designed to have the same static CCT and photopic lux as baseline during all the day, but with changing melanopic lux. (right) In-situ measured spectra from Sequence B SPD, varying from 9 am (blue) to $6 \mathrm{pm}$ (red).

\subsection{Real-time daylight matching}

During the trial's final two weeks, a calibrated spectrometer in the building's roof was installed that was able to measure daylight spectra every few seconds. The spectrometer, connected to a Raspberry $\mathrm{Pi}$, sends the spectral information to the lighting system control unit, which, very fast, finds the channel weights that give the best spectral fitting to the target SPD (LLENAS et al., 2019). Any change in CCT or illuminance in the outdoor environment was smoothly translated inside the office. 


\section{Conclusions}

This article elaborates on an experiment that was conducted during 9 weeks in an office setting without interfering with employees' daily tasks or normal work-load. Different light conditions were used to test whether by designing custom-made SPDs of light in a dynamic way, it is possible to elicit benefits in participant's sleep patterns, alertness, mental effort and mood. The final results will be published elsewhere.

\section{References}

AKERSTEDT T, HUME K, MINORS D, WATERHOUSE J. The subjective meaning of good sleep, an intraindividual approach using the Karolinska Sleep Diary. Percept Mot Skills. 1994;79(1 Pt 1):287-96.

BADIA, P, MYERS, B, BOECKER, M, CULPEPPER, J, HARSH, JR. Bright light effects on body temperature, alertness, EEG and behaviour. Physiology \& Behavior. 1991;50(3):583-8.

BERSON, D, DUNN, F AND TAKAO, M. Phototransduction by retinal ganglion cells that set the circadian clock. Science 2002; Vol. 295(5557), no. 1070-1073.

BONMATI-CARRION, M. A., MIDDLETON, B., et al. 2014. Circadian phase asessment by ambulatory monitoring in humans: Correlation with dim light melatonin onset. Chronobiology International 31(1): 37-51.

CAJOCHEN C. Alerting effects of light. Sleep Med. Rev. 2007; Vols. 11(6), 453-464.

CHELLAPPA, S. L., STEINER, R., BLATTNER, P., OELHAFEN, P., GÖTZ, T., \& CAJOCHEN, C., 2011. Non-visual effects of light on melatonin, alertness and cognitive performance: can blue-enriched light keep us alert?. PloS one, 6(1), e16429.

CRAWFORD, J. R., HENRY, J. D., 2004. The Positive and Negative Affect Schedule (PANAS): Construct validity, measurement properties and normative data in a large non-clinical sample. British Journal of Clinical Psychology, 43(3), 245-265.

GILLBERG M., KECKLUND G., AKERSTEDT T., 1994. Relations between performance and subjective ratings of sleepiness during a night awake. Sleep.;17(3):236-41.

LEWY, A., WEHR, T., GOODWIN, F., NEWSOME, D., AND MARKEY S., 1980. Light suppresses melatonin secretion in humans, Science 210, 1267-1269.

LLENAS, A., CARRERAS, J., 2019. Arbitrary spectral matching using multi-LED lighting systems. Optical Engineering 58(3), 035105.

LUCAS, R.J., PIERSON, S.N., BERSON, D.M. et al., 2014. Measuring and using light in the melanopsin age. Trends in Neuroscience, 37(1):1-9.

REA, M.S., FIGUEIRO, M.G., BIERMAN, A., BULLOUGH, J.D., 2010. Circadian light. $J$ Circadian Rhythms, 8(1):2.

REVELL, V. L., \& SKENE, D. J., 2007. Light-induced melatonin suppression in humans with polychromatic and monochromatic light. Chronobiology international, 24(6), 1125-1137.

SCHEER, F., DOORNEN, L., BUIJS R., 1999. Light and diurnal cycle affect human heart rate: possible role for the circadian pacemaker. J. Biol. Rhythms; Vol. 14(3), no. 202-212.

SCHUBERT, E. F., 2005. Solid-State Light Sources Getting Smart. Science.

TE KULVE, M., SCHLANGEN, L. J., SCHELLEN, L., FRIJNS, A. J., VAN MARKEN LICHTENBELT, W. D., 2017. The impact of morning light intensity and environmental temperature on body temperatures and alertness. Physiology \& behavior, 175, 72-81.

VANDEWALle, G., BALTEAU, E., PHILLIPS, C., DEGUELDRE, C., MOREAU, V., STERPENICH, V., ALBOUY, G., DARSAUD, A., DESSEILLES, M., DANG-VU, T., PEIGNEUX, P., A. LUXEN, D.-J. DIJK, MAQUET, P., 2006. Daytime light exposure dynamically enhances brain responses, Curr. Biol. 16, 1616-1621. 
VERWEY, W.B., VELTMAN H.A., 1996. Detecting short periods of elevated workload: comparison of nine assessment techniques. J Appl Psychol Applied.;3(2):270-85.

VIOLA AU, JAMES LM, SCHLANGEN LJ, DIJK DJ., 2008. Blue-enriched white light in the workplace improves self-reported alertness, performance and sleep quality. Scand J Work Environ Health.;34(4):297-306. 